\title{
Una mirada al rapto en \\ Guadalajara (1885-1933)
}

\author{
Claudia Gamiño Estrada \\ Universidad de Guadalajara \\ cgaminoestrada@hotmail.com
}

Por la palabra de matrimonio. El rapto en Guadalajara (1885-1933) es el título del séptimo libro de la colección del Centro de Estudios de Género, cuya publicación fue posible como resultado del proyecto "La transversalización de la perspectiva de género en la Universidad de Guadalajara". Su autora, Laura Benítez Barba, se ha formado bajo la disciplina de la Historia y ha participado en el rescate y la conservación del Archivo del Supremo Tribunal de Justicia que resguarda la Biblioteca Pública del Estado de Jalisco. Su trayectoria laboral y académica le ha permitido escudriñar los distintos recovecos de la Historia, y se ha inclinado por temas como la delincuencia, el honor y las mujeres, entre otros. Es integrante fundadora de la Red de Historiadores del Delito en las Américas, lo que le ha permitido mantener un diálogo interdisciplinario en el ámbito latinoamericano con los temas de su interés.

Su cercanía con los acervos documentales y su pasión por la Historia la han llevado a documentar y desempolvar el pasado, la vida y situaciones conflictivas a las que se enfrentaban hombres y mujeres a finales del siglo XIX y principios del XX. Ha explorado los archivos y con ello nos abre una ventana para observar, a partir del hecho del rapto, la ciudad de Guadalajara de 1885 a 1933, periodo que va del porfiriato (1878-1910) a la revolución mexicana (1910) y hasta el movimiento cristero (1926-1929), momentos que muestran los distintos conflictos y pugnas en la esfera nacional y local.

Más allá de los grandes problemas nacionales, la autora permite mirar a través de los filtros de la Historia la vida de personajes que, sin habérse- 
lo propuesto, trascendieron y llegaron a nuestros días a partir de las querellas que presentaron. Asímismo, muestra pequeños fragmentos de su vida cotidiana: el rapto, el matrimonio, el amor, el desamor, las relaciones familiares, las actividades laborales de los tapatíos, hombres y mujeres, y que llegan a la actualidad gracias a la mirada de Laura Benítez.

Los contrastes entre el deber ser femenino, planteado por las clases altas de la sociedad, y lo que en la práctica vivían hombres y mujeres en el periodo estudiado resaltan en la investigación desarrollada y plasmada en el libro que ahora forma parte de la colección del Centro de Estudios de Género. Pero qué decir de un libro que desde el título se muestra sugerente, en pleno siglo xxi en que la palabra empeñada ha sido desplazada en muchos casos por el "papelito habla".

En el libro, a decir de la propia autora, se pretende "dar voz a los sin voz, a los hombres y mujeres que tenían que trabajar todo el día para poder subsistir, a las familias que eran víctimas del deshonor causado por el rapto de algunas de sus hijas y a todos aquellos que pretendieron dar inicio a su matrimonio a través de un delito como el rapto".

Para lograr su propósito la autora realiza un recorrido por la legislación, ubicando lo que en materia de rapto estuvo plasmado en ella "desde la antigüedad" hasta el periodo de estudio. Presenta cómo fue definido el rapto desde el punto de vista jurídico, pero también sus implicaciones en la sociedad; cómo se fue transformando de ser un delito contra las familias, la moral pública y las buenas costumbres, hasta llegar a ser un delito sexual, desde luego todo visto a través de lo que se establecía en la legislación. La autora refuerza la temporalidad de su trabajo no sólo a través de la documentación consultada, sino a partir de los códigos y leyes que estuvieron vigentes, y de qué manera en ellos se plasmó el delito. Presenta la definición del rapto desde el Código Penal de Jalisco en 1885, pasando por las transformaciones en 1923 y culminando en 1933, cuando se estableció como un delito sexual.

Para explicar de qué manera el rapto de las mujeres tapatías afectaba el entorno familiar, la autora describe cómo se ha visto la familia, sus integrantes y el papel que cada uno de ellos estaba llamado a representar en el entramado social. Señala que en el periodo de estudio, para justificar la posición y los papeles sociales de mujeres y hombres, se utilizaban los argumentos de superioridad masculina, retomando explicaciones biológicas, y se planteaba que, en el caso de las mujeres, "el útero determinaba su comportamiento emocional y moral, su debilidad mental hacía que su sistema reproductivo fuera más sensible" (p. 62).

Según se plantea, las suposiciones binarias argumentadas desde el punto de vista biológico asociaban al hombre con la fortaleza, el poder, 
en tanto que las mujeres eran vistas como débiles y delicadas. Desde la legislación también había diferenciación entre hombres y mujeres en cuanto a los delitos, y los castigos no se aplicaban de la misma manera. La aplicación de la ley giraba en torno al deber ser masculino y femenino; además, como bien señala la autora, la prensa se encargaba también de difundir y propagar cómo se esperaba que hombres y mujeres se comportaran y planteaba consejos para conseguir un buen partido y lograr un matrimonio "feliz".

El recorrido que la maestra Laura Benítez realiza por la documentación permite conocer quiénes denunciaban los delitos, cómo presentaban las querellas, las actividades a las que se dedicaban los y las denunciantes, las edades y el lugar que ocupaban en la vida familiar, y señala que quienes denunciaban en mayor medida eran las mujeres, las madres de las raptadas; era a ellas a las que correspondía, por tener a su cargo su educación y cuidado. De igual manera, la autora presenta a las mujeres raptadas, sus motivaciones y argumentos para acceder o no a fugarse con el inculpado, a qué se dedicaban, sus oficios y las transformaciones que en la ciudad de Guadalajara se fueron presentando con la incorporación de las mujeres en actividades distintas de las que estaban tradicionalmente llamadas a cumplir.

En el trabajo también se da cuenta de los hombres que denunciaban el rapto de sus hijas; se plantea que para los hombres era más importante reparar el daño antes que saber el lugar donde ellas se encontraban. Al igual que para las mujeres, a través del texto podemos encontrar las actividades a las que se dedicaban los hombres, el papel que se esperaba que cumplieran; querellantes y querellados se encontraron en discursos y argumentaciones que permiten acceder al deber ser femenino y masculino, qué se esperaba de unos y otros y si cumplían o no con los estereotipos, y cómo la sociedad castigaba el no cumplimiento de lo que las elites planteaban como el deber ser.

Habrá que destacar que el libro documenta las transformaciones en el discurso femenino de las mujeres raptadas. No hay una apropiación del discurso de desvalidas, las mujeres raptadas no eran el prototipo de la mujer que las elites esperaban. La violencia era un factor por el que las afectadas decidieron salir de sus casas; la familia, en la práctica, no era el mejor lugar para estar.

Los casos estudiados documentan el valor que se daba a la virginidad femenina, el maltrato familiar, el "depósito" de las mujeres que se fugaban con los novios, las pruebas presentadas por las demandantes y los argumentos de los querellados, los testigos, sus declaraciones y la relación que tenían con querellantes y querellados, con la familia. También 
podemos encontrar una tipología de los delitos sustentada en la documentación que servía de base para la investigación, sus particularidades y de qué manera el delito era difundido y tratado por la prensa tapatía, dónde y bajo qué circunstancias se cometía el delito. Cada tipología o caracterización va acompañada de los casos particulares, lo que permite al lector acompañar en el proceso a los inculpados, a las mujeres raptadas, a sus familias, y visualizar el entorno en el que se consumó el delito.

Se destaca también la presentación de los documentos privados como pruebas contra el demandado para intentar que cumpliera su promesa de matrimonio y realizara la reparación del daño. La autora nos presenta casos concretos que permiten acceder a las cartas a través de las cuales se intentaba argumentar que antes había una relación y que la promesa de formar una familia estaba presente, aunque el inculpado lo negara. Las cartas posibilitan también acceder al ideal de relación que se planteaba, a las distintas vicisitudes que los enamorados tuvieron que afrontar antes de decidir fugarse, pero también muestra las carencias económicas que en algunos casos estaban entre los motivos principales para que los involucrados decidieran hacer vida marital antes de casarse, según explica la autora.

El libro es una ventana que abre la posibilidad de conocer los estereotipos femeninos y masculinos de la sociedad tapatía de finales del siglo XIX y principios del siglo XX; invita a reflexionar sobre las posibilidades de decisión de algunas mujeres a quienes no les importó el honor y decidieron "fugarse con el ser amado", o en su caso, de aquellas que fueron violentadas y optaron por denunciar; también de aquellas que, por ser quienes aportaban el sustento familiar, no permitían que se violentara el honor de sus hijas y por consiguiente el honor familiar.

El deber ser femenino o masculino y el papel de la prensa en la difusión de formas de ser y parecer hombre o mujer se reflejan en una sociedad en la que la mayor parte de los casos documentados hablan de que la trasgresión fue una forma de conseguir que se cumpliera la palabra de matrimonio. Es así como el libro invita a reflexionar a partir del rapto la complejidad de ser hombre o mujer en una sociedad que ha sido considerada como eminentemente conservadora y apegada a los cánones civiles y eclesiásticos.

A través del estudio de las familias de estratos bajos y medios, contrastado con los ideales femeninos planteados por la burguesía y reforzados por la prensa de la época, la autora plantea que las mujeres, además de las labores del hogar, se empleaban en actividades remuneradas que aportaban a la economía familiar.

Recibido: 24/05/2016. Aceptado: 30/06/2016 